\title{
Wheeze and Eosinophilic Airway Inflammation Equals Asthma?
}

\author{
C.E. Brightling \\ Department of Respiratory Medicine and Thoracic Surgery, Institute for Lung Health, Glenfield Hospital, \\ Leicester, UK
}

Eosinophilic lung inflammation can manifest itself as a number of different airway and parenchymal lung diseases [1]. As the name suggests, all eosinophilic lung diseases are characterised by the presence of eosinophilic inflammation, but the cause of the individual diseases is unclear and our understanding of eosinophilic recruitment [2] is incomplete.

In this issue of Respiration, Takayanagi et al. [3] describe a patient with eosinophilic airway inflammation, cough, wheeze and breathlessness and airflow obstruction as seen with asthma. In contrast to asthma, the patient had centrilobular nodules on computed tomography and lung biopsy features suggestive of chronic eosinophilic bronchiolitis. The presence of wheeze and moreover the absence of alveolar shadowing or biopsy evidence of parenchymal lung disease makes this disease distinct from eosinophilic pneumonia. Although it is important to remember that wheeze and airway eosinophilia can occur without asthma [4], it is possible that the case described by Takayanagi et al. may have asthma in association with eosinophilic bronchiolitis.

There are a number of clinical patterns and pathological descriptions of adult chronic bronchiolitis [5]. Some have a clear aetiology such as bronchiolitis associated with connective tissue disease and bronchiolitis in transplanted patients, whereas in others the aetiology is uncertain, such as cryptogenic bronchiolitis and now eosinophilic chronic bronchiolitis. It is important to establish an early pathological diagnosis as management of chronic bronchiolitis is in part guided by the biopsy findings. This is highlighted by the case report of Takayanagi et al. [4] where their patient had been diagnosed as having panbronchiolitis from clinical and radiological findings and had therefore been treated for 3 years with erythromycin. Earlier bronchoscopy and lung biopsy may have resulted in the patient receiving appropriate corticosteroid therapy sooner.

Chronic eosinophilic bronchiolitis is of interest in its own right as a rare eosinophilic lung disease, which, like other eosinophilic lung diseases, is responsive to corticosteroid therapy. Perhaps more importantly, understanding the trigger for and process of eosinophil recruitment to the lung at specific sites, such as the small airways, may inform our knowledge of all eosinophilic lung diseases including asthma.

\footnotetext{
References 1 Allen JN, Davis WB: Eosinophilic lung diseases. Am J Respir Crit Care Med 1994;150: 1423-1438

2 Wardlaw AJ: Molecular basis for selective eosinophil trafficking in asthma: A multistep paradigm. J Allergy Clin Immunol 1999;104: 917-926.

3 Takayanagi N, Kanazawa M, Kawabata Y, Colby TV: Chronic bronchiolitis with associated eosinophilic lung disease (eosinophilic bronchiolitis). Respiration 2001;68:319-322.

4 Ogawa H, Fujimura M, Matsuda T, Nakamura H, Kumabashiri I Kitagawa S: Transient wheeze. Eosinophilic bronchobronchiolitis in acute eosinophilic pneumonia. Chest 1993; 104:493-496.

5 Poletti V, Zompatori M, Cancellieri A: Clinical spectrum of adult chronic bronchiolitis. Sarcoidosis Vasc Diffuse Dis 1999;16:183-196.
}

\begin{tabular}{ll}
\hline KARGER & ( ) 2001 S. Karger AG, Basel \\
Fax +4161306 1234 $34-7931 / 01 / 0683-0242 \$ 17.50 / 0$ \\
$\begin{array}{l}\text { E-Mail karger@karger.ch } \\
\text { www.karger.com }\end{array}$ & $\begin{array}{l}\text { Accessible online at: } \\
\text { www.karger.com/journals/res }\end{array}$
\end{tabular}

Dr. C.E. Brightling

Institute of Lung Health, Department of Respiratory Medicine and Thoracic Surgery

Glenfield Hospital

Leicester LE3 9QP (UK), Tel. +44 1162871471

Fax +44 1162583950 , E-Mail chris.brightling@glenfield-tr.trent.nhs.uk 